\title{
Numerical Analysis Focusing on the Running Safety of an Improved Bogie during Seismic Vibration
}

\author{
Takefumi MIYAMOTO, Dr. Eng. \\ Laboratory Head, \\ Vehicle Mechanics Laboratory, Railway Dynamics Division \\ Hiroaki ISHIDA, Dr. Eng. \\ Director, \\ Railway Dynamics Division
}

\begin{abstract}
We conducted research on the derailment and overturning of railway vehicles as a result of earthquakes. Previous numerical simulation helped to clarify the dynamic behavior and running safety limits of vehicles on a vibrating track, and the results of this simulation are currently adopted in the design of railway structures.

We carried out an experiment using a full-scale half carbody mounted on a Shinkansen bogie placed on a triaxial structural vibration test rig. The simulation analyzed the experimental conditions, and its results were consistent with those obtained from the experiment, thus confirming its validity.

In this paper, we describe the results of analysis and performance improvement for safe running by modifying the parameters of the bogie using our numerical simulation. Our concept exchanged the lateral damper between the carbody and bogie for a High Speed Large Force damper (known as a HSLF damper). This damper performs to generate a larger damping force than that of ordinary dampers only at higher piston speeds. When the HSLF damper is used, a safety effect is gained for vibration over a large frequency range. No adverse effects on ride comfort were found from its operation as an ordinaryperformance damper.
\end{abstract}

Keywords: vehicle, running, safety, earthquake, derailment, damper, improvement

\section{Introduction}

In October 2005, a Shinkansen train was derailed in Japan as a result of the Niigata Chuetsu Earthquake. This was the first ever earthquake-related derailment of a Shinkansen train running at high speed. Following the accident, there were calls for safety countermeasures against earthquakes.

We started developing a Vehicle Dynamics Simulator (VDS) [1] for seismic vibration after the Hyogo-ken Nanbu Earthquake in 1995. A full-scale experiment was carried out on the dynamic behavior of a railway vehicle against heavy track vibration as referred to in [2]. The outcome of the experiment proved the validity of the simulation results.

\section{Numerical simulation}

\subsection{Outline}

Analysis in the previous research on vehicle dynamic behavior in seismicity referred to in [1] focused on a onevehicle model. One vehicle consists of seven rigid bodies in simulation model. Figure 1 shows such a model equipped with one carbody, two bogies and four wheelsets with two wheels each. Eight rails support each wheel from the ground base. The model vehicle has a total of 58 degrees of freedom (each of the seven mass elements has six degrees of freedom, and each of the eight rails has two). Rails are supported elastically in the vertical and lateral directions with the spring and the damper. Each rigid body are connected with the spring or the damper. The feature of this analysis is to take account of large displacement and velocity between the rigid bodies. When the spring and the damper are displaced greatly, the model vehicle is analyzed in elasticity and damping which is different from usual. These equations of motion are automatically derived in the program. Calculations were made using numerical integration at 0.0005 -second intervals using the 4-dimension Runge-Kutta-Gill method.

\subsection{Vehicle and track}

The track structure and many of the parameters used in the vehicles for analysis were taken from the setup of ordinary Shinkansen vehicles. The wheel profile was a Shinkansen arc form, and a JIS $60-\mathrm{kg}$ rail profile was used. We calculated the interaction force between the wheel and rail using Kalker's method with a friction coefficient of 0.3 . The track model was of the slab type on a straight line with no slope or irregularity. Track vibration was input to each wheel in the same phase at a constant running speed of $275 \mathrm{~km} / \mathrm{h}$. 


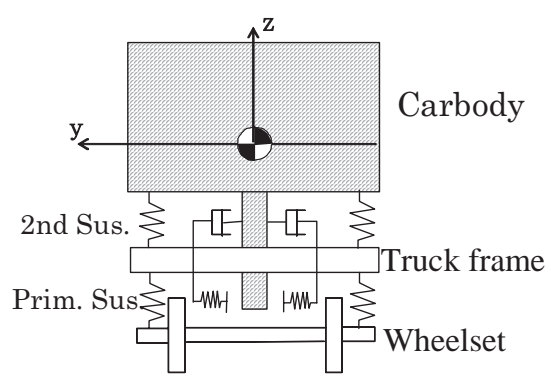

(a) Front view

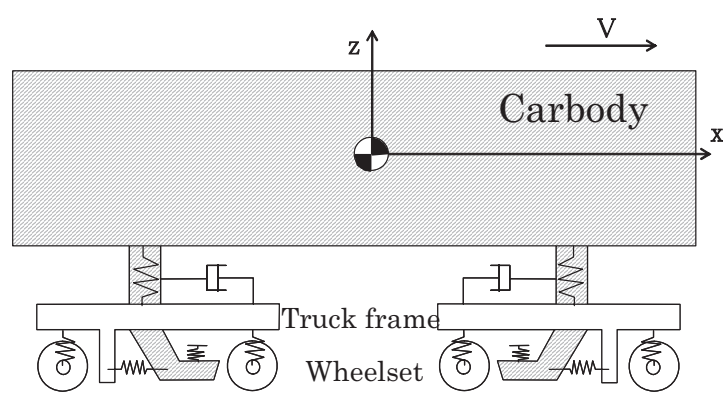

(b) Side view

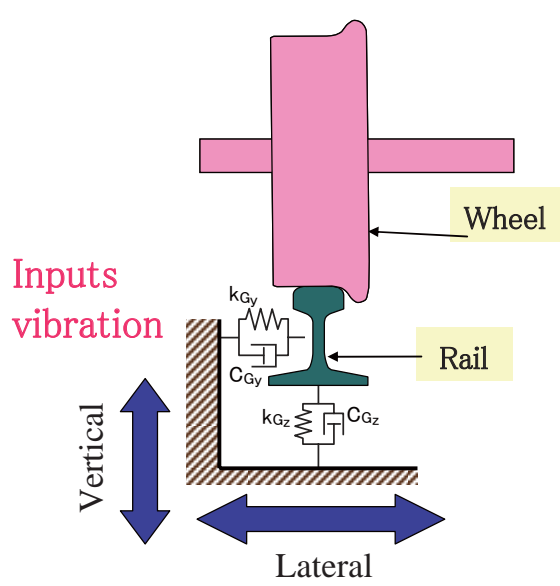

(c) Rail and input vibration model

Fig. 1 Vehicle model for simulation

\subsection{Running safety evaluation method}

Parameters such as the derailment quotient, wheel load reduction ratio and carbody acceleration have been used as indexes in the evaluation of railway vehicle running safety so far. However, when an earthquake occurs, the wheel tread is usually detached from the rail without flange climbing under critical conditions, making it difficult to recognize derailment based on wheel/rail contact forces. We therefore adopted the lateral displacement between the wheel tread center and rail to evaluate the critical conditions of running safety against earthquakes. The limit value of this displacement is set at $\pm 70 \mathrm{~mm}$ as shown in Fig. 2. Using this parameter and value, derailment not only with flange climbing but also with jumping and vehicle overturning can be evaluated accurately. If the wheel returns to the rail after rising and leaving it, running is judged as safe. With a relative displacement of more than $\pm 70 \mathrm{~mm}$, the flange tip of the Shinkansen wheel moves to the field corner (i.e. the outer edge) of the

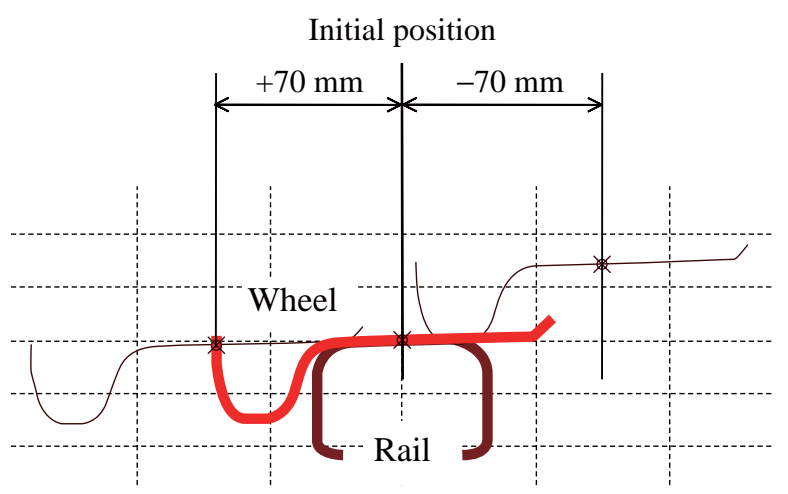

Fig. 2 Evaluation of safety limit

rail in the lateral direction, meaning that it is highly likely to derail.

\subsection{Running safety limits}

Figures 3, 6, 8 and 11 show the running safety limits against sinusoidal vibration. We performed simulation by increasing the amplitude of track vibration every $5 \mathrm{~mm}$ with a constant frequency. If the vehicle derails at a certain amplitude, that amplitude value minus $5 \mathrm{~mm}$ is determined as the running safety limit for each frequency. The line in the graph connecting these points represents the critical displacement amplitude corresponding to every frequency of earthquake-related sine wave vibration. The vehicle runs safely if the combination of amplitude and frequency is within the area below the limit line.

\section{Improvement of safety during earthquakes}

\subsection{Modified bogie parameters}

The influence of a number of bogie parameters on running safety limits was investigated. In the case of each modified parameter, little effect was found in the input frequency range of $0.3-3.0 \mathrm{~Hz}$, excluding the lateral

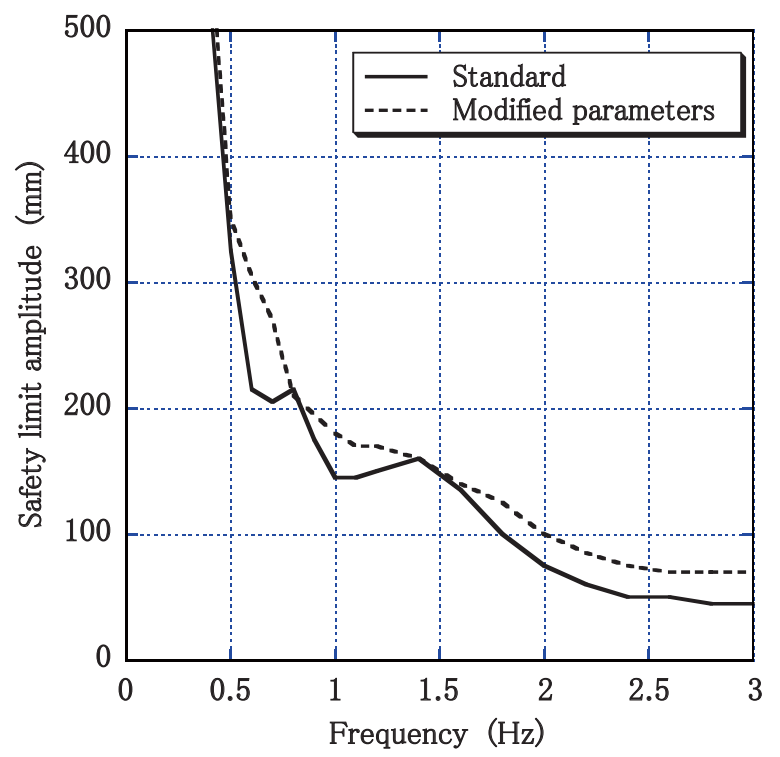

Fig. 3 Running safety limits for modified parameters 
Table 1 Modified bogie parameters

\begin{tabular}{|l|l|}
\hline Parameter & Change \\
\hline $\begin{array}{l}\text { Damper coefficient of } 2^{\text {nd }} \text { sus- } \\
\text { pension }\end{array}$ & $2 \times$ standard \\
\hline $\begin{array}{l}\text { Damper coefficient of lateral } \\
\text { damper }\end{array}$ & $2 \times$ standard \\
\hline $\begin{array}{l}\text { Gap of vertical stopper between } \\
\text { body and truck frame }\end{array}$ & $70 \mathrm{~mm} \rightarrow 130 \mathrm{~mm}$ \\
\hline $\begin{array}{l}\text { Gap of vertical stopper between } \\
\text { truck frame and axle box }\end{array}$ & $\begin{array}{l}\text { Upper: } 24 \mathrm{~mm} \rightarrow 60 \mathrm{~mm} \\
\text { Lower: } 28 \mathrm{~mm} \rightarrow 35 \mathrm{~mm}\end{array}$ \\
\hline $\begin{array}{l}\text { Gap of lateral stopper between } \\
\text { body and truck frame }\end{array}$ & $20 \mathrm{~mm} \rightarrow 40 \mathrm{~mm}$ \\
\hline
\end{tabular}

damper between the bogie and carbody. The five modified parameters in Table 1 were combined, with the results as shown in Fig. 3. Although these modifications can improve performance in running safety limits, some of the parameters are very important for running stability. When changing parameters, it is therefore necessary to consider maintaining the usual levels of passenger comfort and safety.

\subsection{Proposed device}

As the performance of the bogie must not cause a deterioration in normal running performance, earthquake safety improvement requires a new device. A number of ideas have been introduced to investigate the efficiency of raising safety using VDS, and two of these are outlined below.

\subsubsection{Crushable stopper}

When vehicles vibrate strongly due to large-scale seismicity, an excessive load acts on lateral stoppers between the bogie and carbody, and the stopper seat is crushed as shown in Fig. 4. This spread mechanism of the lateral stopper's gap is called a crushable stopper. Figure 4 shows an example of a crushable stopper model (CS) using a mechanical fuse bolt. The gap in a lateral stopper expands to $60 \mathrm{~mm}$ normally, as shown in the figure. In the experiment, we did not consider energy absorption stemming from the plastic deformation of the component in the process of stopper crushing. Modeling was performed with focus on the function by which the area between stopper gaps becomes large. Analysis considered the model, whose spring characteristic changes immediately after exceeding the crush threshold value from solid line to dotted line in Fig. 5. Figure 6 shows the effect of CS on running safety limits for the case of a $300-\mathrm{kN}$ load acting on a crushable stopper. The dotted line for the CS in Fig. 6 indicates that the running safety limit improves for vibration with a frequency of $1.8 \mathrm{~Hz}$ or more, but falls for frequencies below this level. For the purpose of compensating the weak points of the low frequency region, Fig. 6 shows the results obtained when combining the five modified parameters shown in Table 1, with the CS results given as a thin solid line. The results of the crushable stopper with modified parameters raised the safety limit amplitudes in the frequency range of $0.3-3.0 \mathrm{~Hz}$.

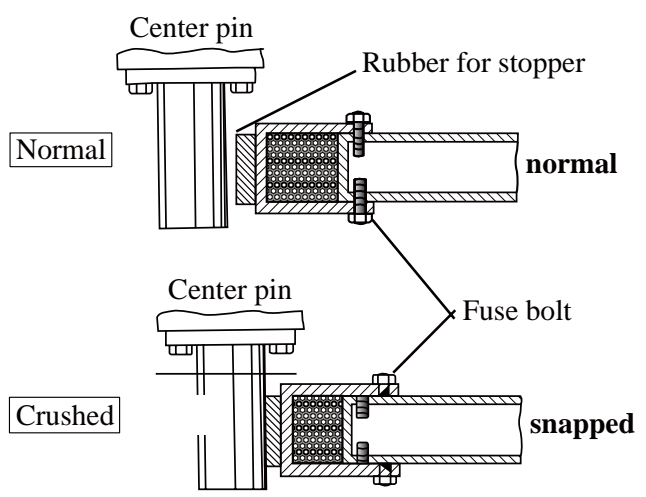

Fig. 4 Crushable stopper (CS) model (Mechanical fuse type)

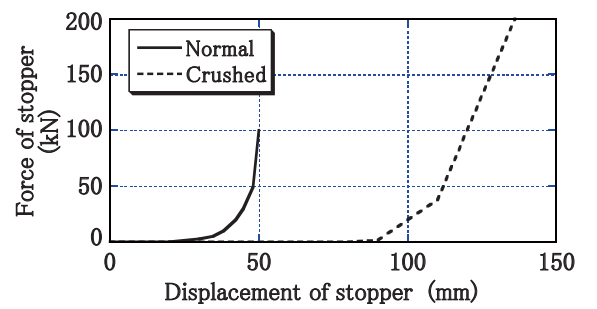

Fig. 5 Performance curve for crushable stopper

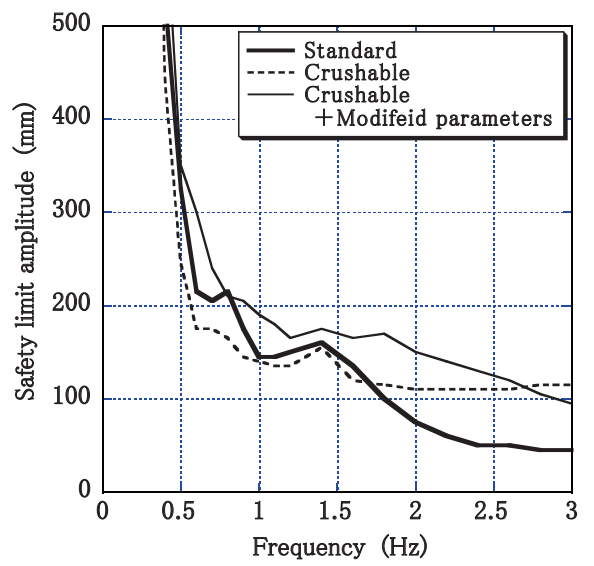

Fig. 6 Running safety limits with crushable stopper

\subsubsection{High damping force for lateral damper}

In investigating the influence of bogie parameters on running safety limits, an increase in the damping force of the lateral damper between the carbody and bogie has an improvement effect on safety. Since running comfort for passengers and the running stability of the bogie are affected, however, the damping coefficient of lateral dampers cannot be easily changed as a measure against earthquakes. The case of a large damping force in a big earthquake was simulated without changing the ordinary damping characteristics using a lateral High Speed Large Force (HSLF) damper. The characteristics of the damping force generated with the HSLF damper are shown in Fig. 7. The use of the HSLF damper presupposed that the damping force becomes larger in proportion to the damper speed than a standard damper when the ordinary damper speed of $0.2 \mathrm{~m} / \mathrm{sec}$ is exceeded. The running safety limits when using the HSLF damper are shown in 
Fig. 8. When the proposed HSLF damper is used, the safe marginal amplitude becomes high in the large range with an input frequency of $0.6 \mathrm{~Hz}$ or more.

Next, the effect of the HSLF damper is outlined in detail. Operation of wheel loads and lateral forces with the standard and HSLF dampers produced large vibration, and the lateral stopper force, lateral damper power and the distance the wheel jumped from the rail are shown in Figs. 9 and 10. Figure 9 indicates the results with a low input frequency of $0.6 \mathrm{~Hz}$, and Fig. 10 shows the same for an input frequency of $2.0 \mathrm{~Hz}$.

At low input frequencies as shown in Fig. 9, the distance the wheel jumps became large with amplitudes of $150 \mathrm{~mm}$ or more, the flange top rode on the rail and derailment occured when the wheel descended. A vertical stopper between the carbody and bogie generated a large force of over $200 \mathrm{kN}$, and was in contact until just before the derailment. With the HSLF type, the lateral damper power generated a larger damping force than with the standard type, the force of lateral stopper and lateral stopper made it small, and the wheel-jump distance decreased. As a result, vehicles equipped with HSLF dampers did not derail.

With high input frequency as shown in Fig. 10, in the case of the standard damper a lateral force exceeding 300 $\mathrm{kN}$ occurred with the left wheel, and a large force of around $500 \mathrm{kN}$ occurred in the lateral stopper. As a result, the right wheel rose by about $70 \mathrm{~mm}$, the flange top rode on the rail and derailment occurred when it descended. When the HSLF damper was used after the occurrence of a large lateral force, it generated a large damping force and made the lateral stopper force small at $300 \mathrm{kN}$ or less. As a result, the wheel jumped but did not derail.

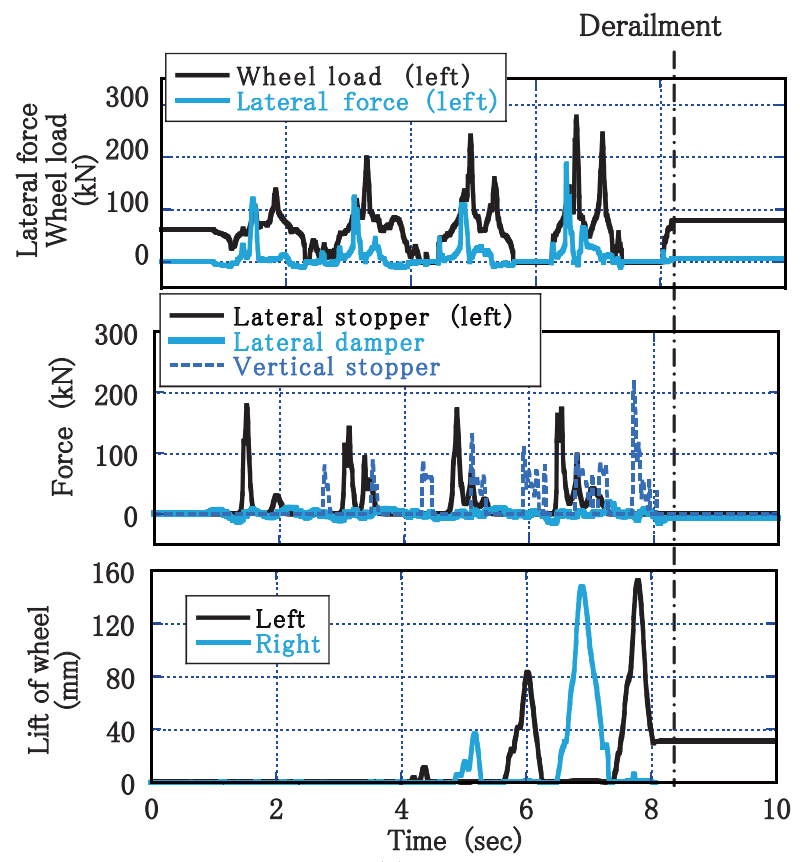

(a) Standard

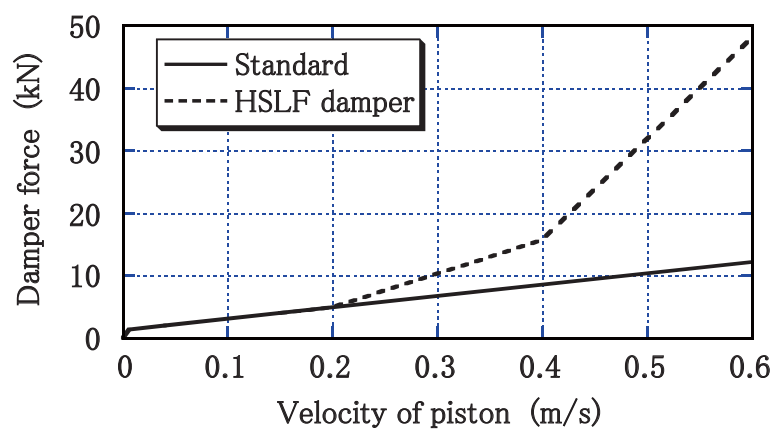

Fig. 7 Performance of High Speed Large Force (HSLF) damper

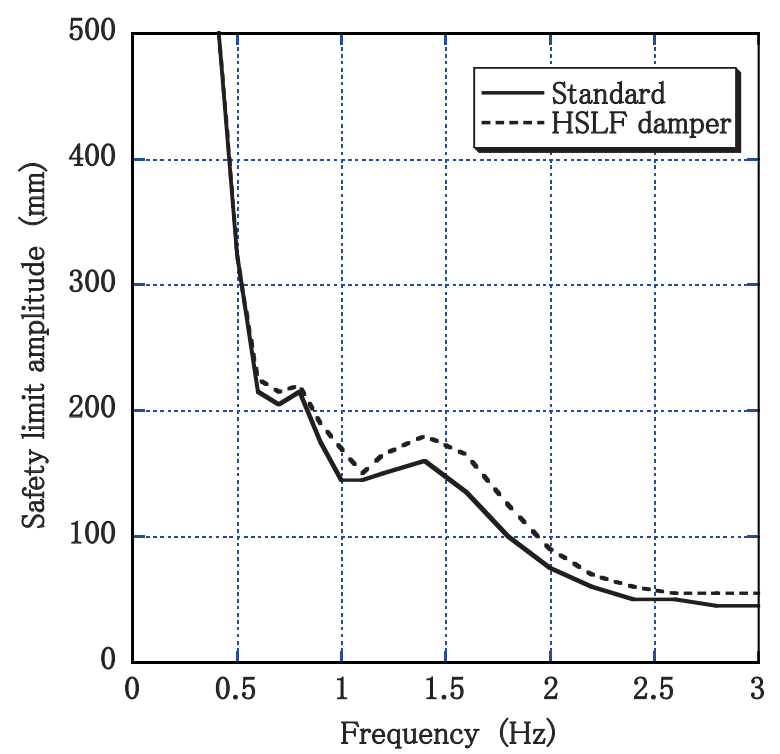

Fig. 8 Running safety limits with the High Speed Large Force (HSLF) damper

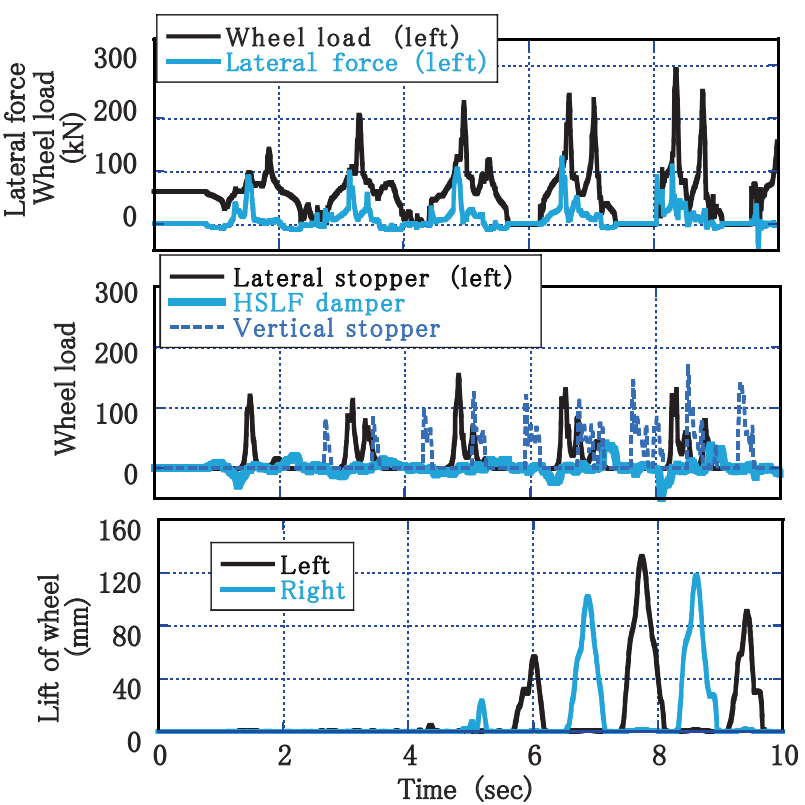

(b) High Speed Large Force (HSLF) damper

Fig. 9 Simulation results with the High Speed Large Force (HSLF) damper fitted (frequency $0.6 \mathrm{~Hz} \cdot C$ amplitude $225 \mathrm{~mm}$ ) 


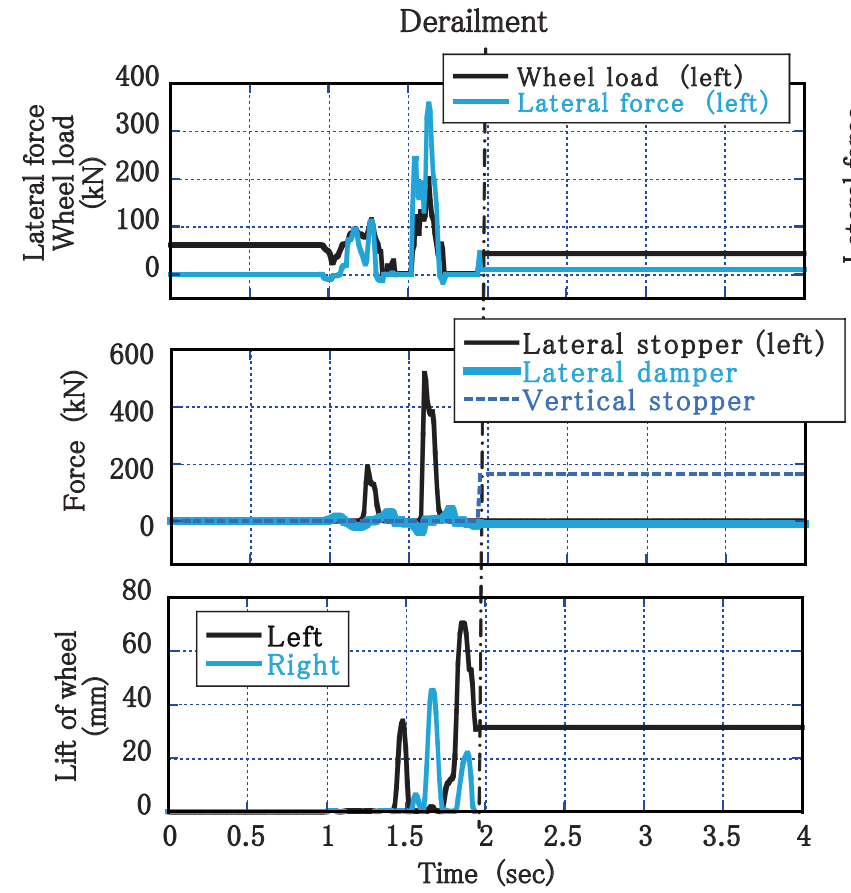

(a) Standard
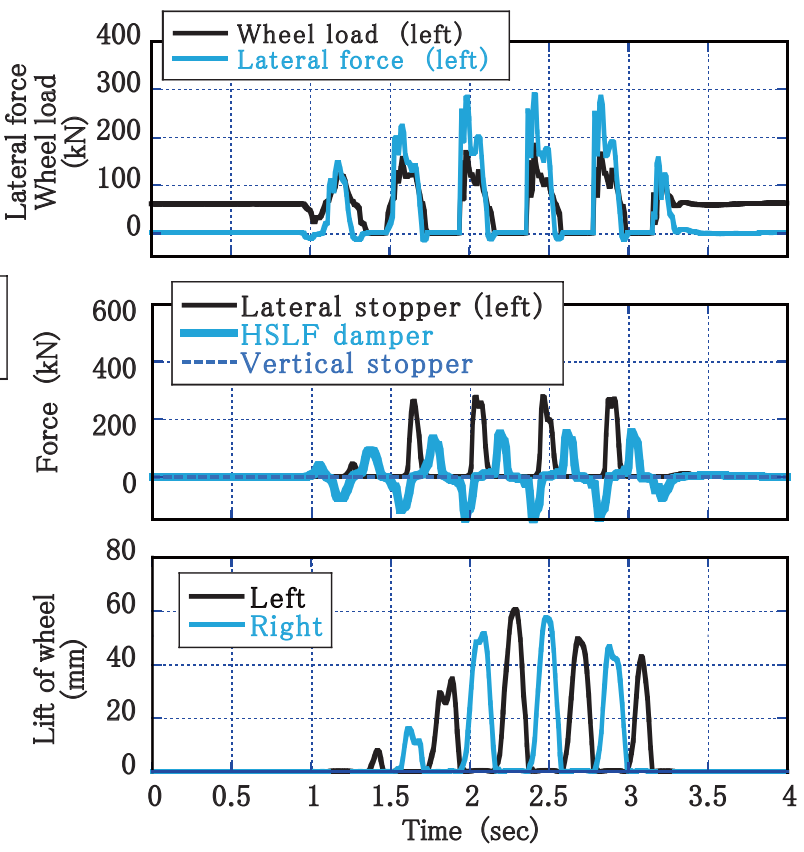

(b) High Speed Large Force (HSLF) damper

Fig. 10 Simulation results with the High Speed Large Force (HSLF) damper fitted (frequency $2.4 \mathrm{~Hz} \cdot$ Camplitude $60 \mathrm{~mm}$ )

\subsubsection{Combined use of CS and HSLF damper}

Calculation was also confirmed for a case combining CS and HLSF. Under this setup, performance was improved by adjusting each characteristic. The CS2 with changed performance was operated at $200 \mathrm{kN}$, and for the HSLF2 damper with changed performance, the maximum damping force was set as $100 \mathrm{kN}$. The running safety limits under this combination with changed performance (Crushable2 + HSLF damper2) are as shown in Fig. 11.

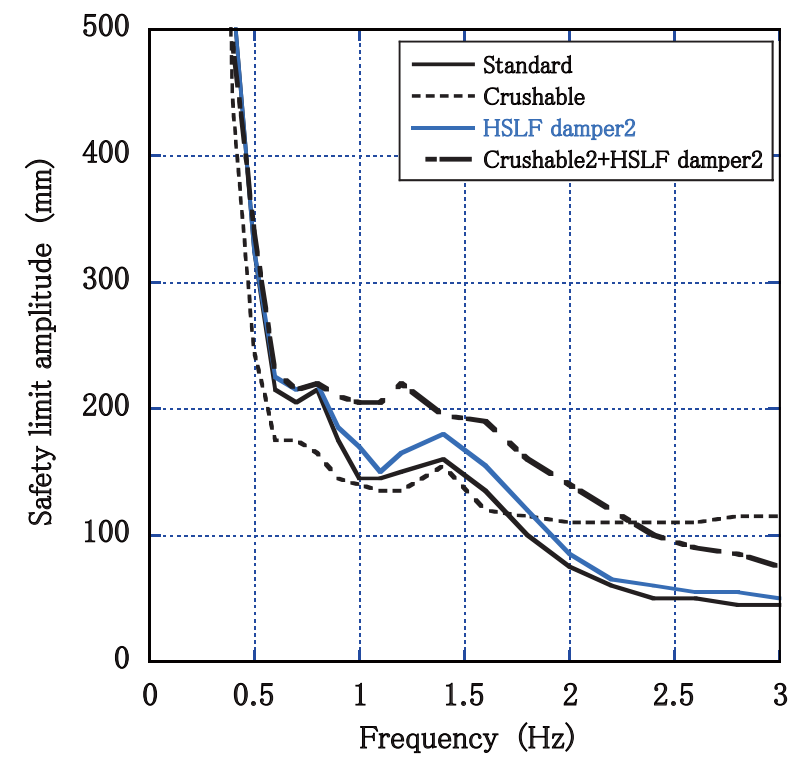

Fig. 11 Running safety limits with combined use of crushable stopper and High Speed Large Force (HSLF) damper
The safety limit amplitude becomes lower than the result with only a crushable stopper at an input frequency of 2.4 $\mathrm{Hz}$ or more. However, a larger effect than with the standard version is seen in the large range with an input frequency of $0.6 \mathrm{~Hz}$ or more. It is conceivable that both advantages can be harnessed and running safety improved in earthquakes through extension of the lateral stopper gap and enlargement of the damping force by a lateral damper.

\section{Conclusion}

Investigation of various factors to improve the safety of railway operations in earthquake-prone areas has produced some advanced results. Here, numerical simulation demonstrated the feasibility of anti-earthquake measures that can be implemented on vehicles. HSLF dampers are shown to be effective in the prevention of likely derailment, and further experimental research is currently in progress on such dampers. The authors also plan to examine the actual structure of crushable stopper and improvement safety during train running through combination with HSLF dampers.

\section{References}

[1] T.Miyamoto, H.Ishida, M.Matsuo: "Running Safety of Railway Vehicle as Earthquake Occurs," Quart Rep. of RTRI, Vol.38, No.3, pp.117-122, 1997.9.

[2] T.Miyamoto, M.Sogabe, T.Shimomura, Y.Nishiyama, N.Matsumoto, M.Matsuo: "Railway Vehicle Dynamic Behavior against Large-Amplitude Track Vibration," Quart Rep. of RTRI, Vol.45, No.3, pp.111-115, 2004. 